\title{
(6) OPEN ACCESS \\ Duration of death investigations that proceed to inquest in Australia
}

\author{
David M Studdert, ${ }^{1}$ Simon J Walter, ${ }^{2}$ Celia Kemp, ${ }^{3}$ Georgina Sutherland ${ }^{3}$
}

\begin{abstract}
- Additional material is published online only. To view please visit the journal online (http://dx.doi.org/10.1136/ injuryprev-2015-041933).

${ }^{1}$ Center for Health Policy/ PCOR, Stanford University School of Medicine, Stanford, California, USA

${ }^{2}$ Department of Statistics, University of California, Berkeley, California, USA ${ }^{3}$ Melbourne School of Population and Global Health, University of Melbourne, Parkville, Australia; Email: celia.m.kemp@gmail.com
\end{abstract}

\section{Correspondence to} Professor David Studdert, Center for Health Policy / PCOR, Stanford University School of Medicine, 117 Encina Commons, Stanford, CA 94305, USA; studdert@stanford.edu

Received 10 December 2015 Revised 31 March 2016 Accepted 20 April 2016 Published Online First 19 July 2016

\section{SLinked}

- http://dx.doi.org/10.1136/ injuryprev-2016-042076

\section{CrossMark}

To cite: Studdert DM Walter SJ, Kemp C, et al. Inj Prev 2016;22:314-320.

\section{ABSTRACT}

Background Recent government inquiries in several countries have identified the length of time it takes coroners to investigate deaths due to injury and other unnatural causes as a major problem. Delays undermine the integrity of vital statistics and adversely affect the deceased's family and others with interests in coroners' findings. Little is publicly known about the extent, nature and causes of these delays.

Methods We used Kaplan-Meier estimates and multivariable regression analysis to decompose the timelines of nearly all inquest cases $(n=5096)$ closed in coroners' courts in Australia between 1 January 2007 and 31 December 2013.

Results The cases had a median closure period of 19.0 months ( $95 \% \mathrm{Cl} 18.4$ to 19.6). Overall, $70 \%$ of cases were open at 1 year, $40 \%$ at 2 years and $22 \%$ at 3 years, but there was substantial variation by jurisdiction. Adjusted analyses showed a difference of 22 months in the average closure time between the fastest and slowest jurisdictions. Cases involving deaths due to assault ( +12.2 months, $95 \% \mathrm{Cl} 7.8$ to 17.0$)$ and complications of medical care (+9.0 months, $95 \%$ CI 5.5 to 12.3) had significantly longer closure periods than other types of death. Cases that produced public health recommendations also had relatively long closure periods (+8.9 months, $95 \% \mathrm{Cl} 7.6$ to 10.3 ).

Conclusions Nearly a quarter of inquests in Australia run for more than 3 years. The size of this caseload tail varies dramatically by jurisdiction and case characteristics. Interventions to reduce timelines should be tried and carefully evaluated.

\section{INTRODUCTION}

A succession of government inquiries into coronial systems-in Australia, ${ }^{12}$ Canada, ${ }^{3}$ New Zealand, ${ }^{45}$ the $\mathrm{UK}^{6-8}$ and Ireland ${ }^{9}$ - have identified the length of time it takes coroners to investigate deaths as a major problem. Delays in death investigations are also a frequent target of media reports around the world. ${ }^{10} 11$ The most serious concerns regarding delays centre on death investigations that proceed to an inquest. In Australia, nearly 20000 deaths, or $12 \%$ of all deaths, are reported to coroners each year. For about 1 in 20 of these reported deaths, the coroners' investigation involves an inquest. ${ }^{12}$

Delays in death investigations have a range of negative consequences. They may diminish the quality of the evidence, particularly the reliability and utility of witness testimony. ${ }^{13}$ They can be frustrating to institutions that frequently have interests in the findings of death investigations, including hospitals, employers and government agencies. Prolonged death investigations also threaten public health objectives in several ways. First, coroners in many countries, including Australia, are empowered to incorporate recommendations into their findings-essentially, reforms and countermeasures the coroner identifies as promising for preventing causes or risk factors for deaths like the one under investigation. Recipients of such recommendations often accept them, ${ }^{14}$ and coroners findings have been linked to a number of successful prevention initiatives. ${ }^{15} 16$ Thus, delays in producing findings and recommendations may prolong the public's exposure to remediable risks. ${ }^{12} 41416$

Second, slow case closure creates lags in death certification that may undermine the quality of vital statistics and public health surveillance. ${ }^{17}$ A widely discussed example of this in Australia relates to inaccuracies in official suicide statistics. ${ }^{18}{ }^{19}$ Finally, long waits for death investigation findings are stressful for family and friends of the deceased. Emotional closure may not be possible before an official ruling on what happened is handed down. ${ }^{10} 20-23$ The same may be true for financial closure; life insurance and superannuation payouts, for example, are sometimes contingent on a coroner's finding. ${ }^{11}{ }^{24}$ Considering the large caseloads coroners manage, the accumulation of such private aggravations become a public health problem if delays are common and long.

There is limited publicly available information on the duration of coronial death investigations. When statistics are reported, it is in crude formtypically as counts or proportions of backlogged cases, or overall means or medians for closure periods. ${ }^{14525}$ While simple statistics can hint at the extent of the problem, they provide an incomplete picture and shed little light on the nature of the caseload 'tail'.

Australia's unique national collection of death reports to coroners, the National Coroners Information System (NCIS), permits more detailed analysis of case duration. We analysed a sample of approximately 5000 inquest cases closed between 2007 and 2013-nearly all of the inquests closed in Australia over this 7-year period. Our goals were to describe the time intervals between death reports and the issuing of inquest findings and to identify characteristics of particularly long-running cases.

\section{METHODS}

\section{Coroners' courts and inquests in Australia}

Coroners' courts in Australia are state-based jurisdictions. The definition of deaths that must be reported to them varies slightly across the six states and two territories. In general, unexpected, unnatural or violent deaths must be reported, including those related to an injury or accident. Deaths 
occurring while a person is held in a state facility (eg, prison) must be reported, as must certain medical and surgical procedure-related deaths and deaths in which the identity of the deceased or the cause of death is unknown.

Inquests are formal judicial hearings into the causes and circumstances of death, in which the parties involved present evidence, cross-examine witnesses and are often represented by lawyers. All other death investigations are handled in chambers', where findings are reached on the basis of desk-based reviews of witness statements, police and medical examiner reports and other forensic evidence. ${ }^{16}$

Our analysis focused on inquests (hereafter, 'inquest cases'). A description of how coroners select cases for inquest is provided in the online supplementary appendix.

\section{Data and study sample}

Data for this study came from the NCIS, an electronic data storage and retrieval system which contains information on all deaths investigated by state and territory coroners. ${ }^{26}$ (Details of the NCIS are provided in the online supplementary appendix.) We identified all deaths in Australia recorded as having been closed at inquest between 1 January 2007 and 31 December $2013(\mathrm{n}=5459)$. The data extraction date was 17 July 2014, which allowed about 6 months for coroners' clerks to upload NCIS information pertaining to the most recently closed cases. A review of upload lags by state and year indicates we are likely to have missed no more than an inconsequential number of closed cases with this grace period (see online supplementary appendix).

Many of the inquest cases closed in New South Wales in 2009 had implausibly short closure periods, suggesting a systematic problem with data coding. We dropped all cases from that state and year $(n=363$, details provided in the online supplementary appendix). This left a final analytic sample of 5096 inquest cases.

\section{Variables}

The NCIS includes a set of coded and free text fields which capture characteristics of the deceased, the death and the case. The age, sex, marital status and employment status of the deceased are recorded in most cases. Key dates are also available for each reported death, including the date of the death, the date the death was reported to the coroner and the date the coroner closed the case; closure dates generally indicate the date findings were delivered. The primary outcome in our analyses was the case 'closure period', defined as the number of 30.4-day months that elapsed between the date a death was notified to the coroner and the date the investigation into that death was closed.

The NCIS records whether the death was due to natural, external or unknown causes. For deaths judged to be due to external causes, the coroners' determination of type of external cause is classified into 10 categories of 'intent' (unintentional injury, suicide, etc). Using other information available in NCIS, we reclassified external-cause deaths into nine categories: suicide, transport, poisoning, fall, drowning, complications of medical care, assault, other external cause and undetermined. A variable indicating location of death was constructed by mapping a remoteness area value from the Accessibility/ Remoteness Area Index of Australia to the postcode of each death location. ${ }^{27}$ Further details of how the external cause and location of death variables were constructed are provided in the online supplementary appendix.

\section{Analysis}

The unit of analysis was inquest cases. We computed the proportion of cases remaining open over time, overall and then by cause-of-death and jurisdiction, respectively; we present these as survival plots. The variance of the proportion open was estimated using Greenwood's formula. ${ }^{28}$

To estimate the association between each covariate and case duration, we used multiple linear regression. The outcome was the number of months a case took to close. The explanatory variables were sex and age of the deceased, cause of death, remoteness of the location of death, state, central or regional court and whether a public health recommendation or warning was issued in the case. The residuals displayed heteroskedasticity and were not Gaussian, so we used the bootstrap with case resampling to construct CIs. To address missing covariate information, we imputed missing values using chained equations for each resample. ${ }^{29-31}$

All analyses were conducted using R (Version 3.1.1).

\section{Ethics approval}

The study was approved by the Human Research Ethics Committee at the Victorian Department of Justice.

\section{RESULTS}

\section{Sample characteristics}

Sixty-eight per cent of the deceased were male and 29\% were employed at the time of their death (table 1). Death was judged to be due to external causes in $68 \%$ of the cases and to natural causes in $25 \%$; the rest were undetermined. The most prevalent types of external-cause deaths were transport incidents $(23 \%$ of all deaths), suicide (14\%), poisoning (9\%) and complications of medical care $(5 \%)$.

New South Wales and Victoria accounted for 68\% of the cases. In $28 \%$ of cases, coroners' findings included recommendations or warnings aimed at improving public health and safety.

\section{Case closure periods}

Overall, the inquest cases took a median of 19.0 months $(95 \%$ CI 18.4 to 19.6 ) between the date of report to the coroner and the date findings were issued. Seventy per cent of the cases were open at 1 year, $40 \%$ at 2 years, $22 \%$ at 3 years and $12 \%$ at 4 years (figure 1A). At 5 years, $6 \%$ of the cases $(n=318)$ remained open.

There was wide variation in the length of case closure periods by jurisdiction (figure 1B). At 2 years, for example, $21 \%$ of cases were open in the Northern Territory and 26\% of cases were open in New South Wales, whereas much larger proportions remained open in South Australia (87\%), Queensland (58\%), Tasmania (53\%) and Western Australia (52\%). At 4 years, $2 \%$ and $7 \%$ of cases remained open in the Northern Territory and New South Wales, respectively, while 18\% were open in Victoria and South Australia.

Case duration also varied widely by cause of death (figure 1C). Deaths due to complications of medical care and assault were especially long-running. Among medical deaths, 74\% were open at 2 years, $34 \%$ at 4 years, and $18 \%(n=42)$ at 5 years. Among assaults, $61 \%$ were open at 2 years, $31 \%$ at 4 years and $22 \%$ $(n=53)$ at 5 years. By contrast, deaths determined to be due to natural causes closed fastest. Deaths due to drowning, falls and suicide were also relatively fast, with $32 \%-41 \%$ open at 2 years and $6 \%-7 \%$ open at 4 years. 
Table 1 Characteristics of deceased, deaths and cases ${ }^{*} \dagger$

\begin{tabular}{|c|c|c|}
\hline Characteristics & $\mathbf{n}$ & Per cent \\
\hline \multicolumn{3}{|l|}{ Deceased } \\
\hline Male & 3449 & 68 \\
\hline \multicolumn{3}{|l|}{ Age, years } \\
\hline$<18$ & 577 & 11 \\
\hline $18-25$ & 487 & 10 \\
\hline $26-40$ & 1254 & 25 \\
\hline $41-60$ & 1424 & 28 \\
\hline $61+$ & 1208 & 24 \\
\hline \multicolumn{3}{|l|}{ Marital status } \\
\hline Never married & 1806 & 35 \\
\hline Married (including de facto) & 1634 & 32 \\
\hline Divorced or separated & 456 & 9 \\
\hline Widowed & 239 & 5 \\
\hline \multicolumn{3}{|l|}{ Employment status } \\
\hline Employed & 1488 & 29 \\
\hline Retired/pensioner & 1275 & 25 \\
\hline Unemployed or home duties & 869 & 17 \\
\hline Student & 343 & 7 \\
\hline Prisoner & 236 & 5 \\
\hline Other & 288 & 6 \\
\hline \multicolumn{3}{|l|}{ Death } \\
\hline \multicolumn{3}{|l|}{ Cause } \\
\hline Natural & 1273 & 25 \\
\hline External & 3462 & 68 \\
\hline Transport & 1174 & 23 \\
\hline Suicide & 720 & 14 \\
\hline Poisoning & 466 & 9 \\
\hline Assault & 247 & 5 \\
\hline Complications of medical care & 239 & 5 \\
\hline Fall & 207 & 4 \\
\hline Drowning & 207 & 4 \\
\hline Other external cause & 359 & 7 \\
\hline Undetermined & 361 & 7 \\
\hline \multicolumn{3}{|l|}{ Location } \\
\hline Major city & 2865 & 56 \\
\hline Inner regional & 1074 & 21 \\
\hline Outer regional & 496 & 10 \\
\hline Remote & 140 & 3 \\
\hline Very remote & 166 & 3 \\
\hline \multicolumn{3}{|l|}{ Case } \\
\hline \multicolumn{3}{|l|}{ Jurisdiction } \\
\hline New South Wales & 2221 & 44 \\
\hline Victoria & 1219 & 24 \\
\hline Queensland & 573 & 11 \\
\hline Western Australia & 517 & 10 \\
\hline South Australia & 203 & 4 \\
\hline Australian Capital Territory & 185 & 4 \\
\hline Northern Territory & 123 & 2 \\
\hline Tasmania & 55 & 1 \\
\hline Central court & 3715 & 73 \\
\hline Recommendation or warning issued & 1404 & 28 \\
\hline
\end{tabular}

\section{Multivariable predictors of case duration}

Multivariable analyses identified several strong predictors of case duration (table 2). Compared with cases in New South
Wales, cases were significantly longer on average in South Australia (+11.9 months), Queensland (+8.2 months), Victoria (+7.5 months) and Western Australia (+3.8 months). Northern Territory cases, on the other hand, ran 10.1 months shorter than those in New South Wales. Thus, the average case closure period was almost 2 years longer in South Australia than it was in the Northern Territory.

Most of the same causes of deaths that were associated with long timelines in unadjusted analyses reappeared in adjusted analyses. Specifically, deaths due to assault (+12.2 months) and complications of medical care (+9.0 months) ran significantly longer than cases involving other types of death. Cases involving deaths due to natural causes ( -6.6 months), drowning ( -4.3 months) and suicide ( -4.6 months) ran significantly shorter.

Cases involving deaths that occurred in very remote areas closed 6.5 months earlier than cases involving deaths that occurred in cities. Cases handled in central courts ran 6.9 months longer than those handled in regional courts. And compared with cases that did not produce recommendations or warnings, cases that did ran 8.9 months longer.

\section{DISCUSSION}

This study applied standard epidemiologic methods to a national sample of coronial death investigations in order to decompose the timelines in these cases. The cases took an average of 19 months to close, but there was a long right tail in the distribution of case closure periods: $70 \%$ of inquest cases were open at 1 year, $40 \%$ at 2 years and nearly one-quarter at 3 years. Closure periods differed systematically by cause of death, with investigations into deaths due to assault and medical complications taking substantially longer to complete than investigations into other types of death. Large geographic differences were also apparent: nearly 2 years separated the jurisdictions with the longest and shortest average closure periods. In addition, cases that produced recommendations for improving public health and safety ran nearly 10 months longer on average than cases that did not.

One noted commentator has called delays a 'bane' of inquest systems in Australia, New Zealand and the UK. ${ }^{23}$ Prolonged death investigations may undercut the work of public health and vital statistics agencies, delay useful recommendations for preventing injury and have pernicious effects on the deceased's family and loved ones. Given these considerable social costs, it is remarkable that so little information is available on the duration of death investigations. Our results expose the inadequacy of the type of crude timeline metrics (eg, mean and median closure periods) available today, and on which commissions of inquiry have repeatedly had to rely. Why this troubling aspect of the coronial system has not attracted more sophisticated measurement is unclear. Disinterest among lawyers and legal institutions in analysing and understanding caseloads (as opposed to individual cases) is one contributing factor; $;^{32} 33$ data constraints are probably another.

Why do so many inquest cases in Australia take more than 3 years to close? Although the spotlight naturally falls on the action (or inaction) of coroners themselves, drivers of delay are likely to be multifactorial. Coroners have pointed to resourcing issues, particularly insufficient staff, as well as deficient information technology and the tardy provision of information needed to conclude their investigation. ${ }^{34} 35$ It is also important to recognise that inquests depend on a chain of activity. Essential raw material for inquest findings often comes from police reports 


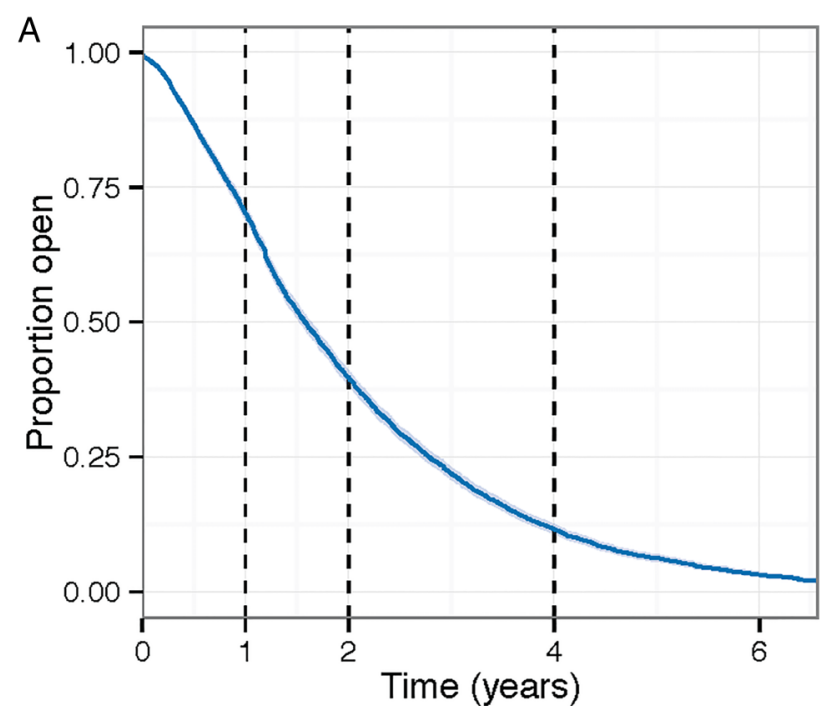

B

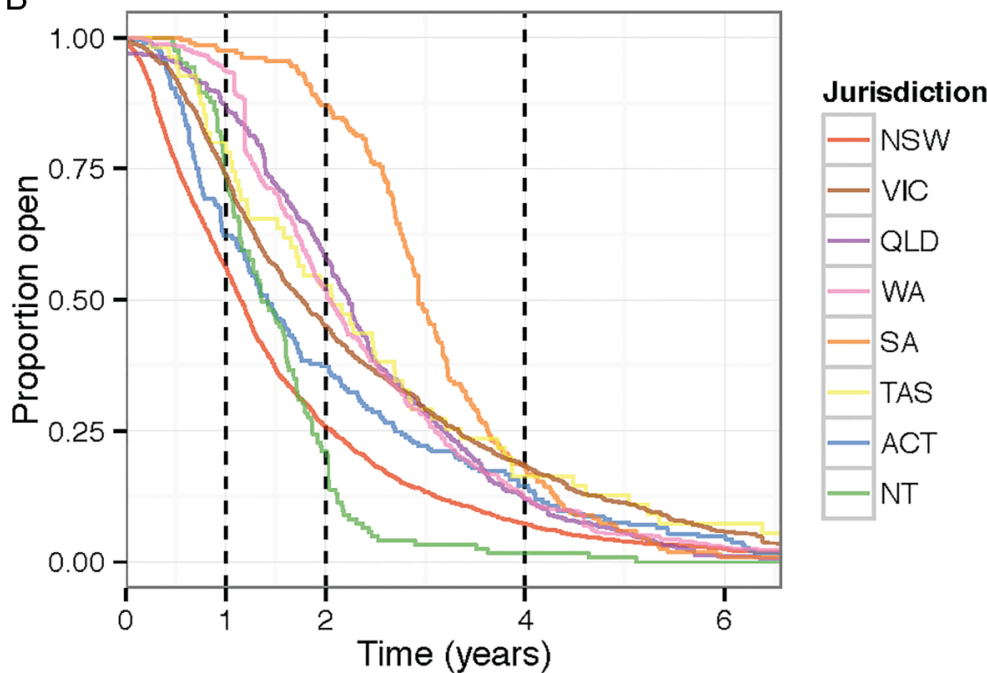

C

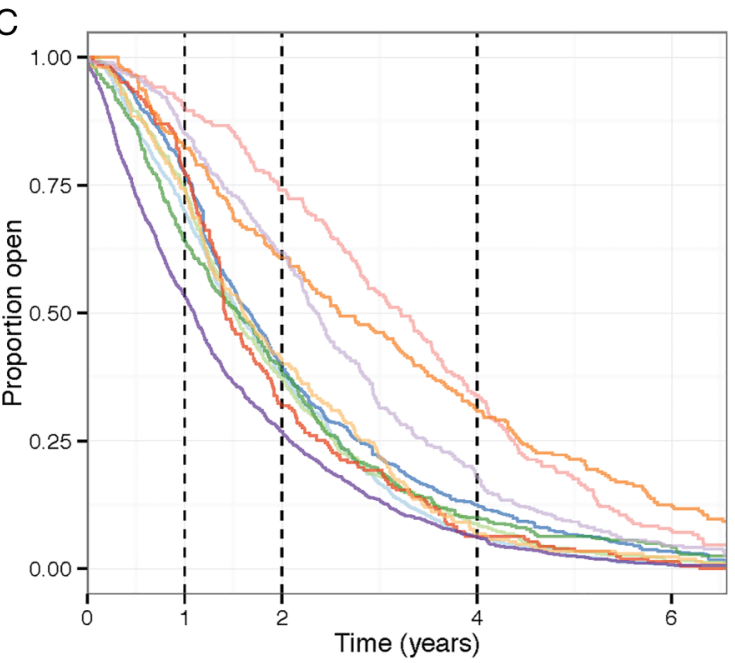

\section{Cause of death}

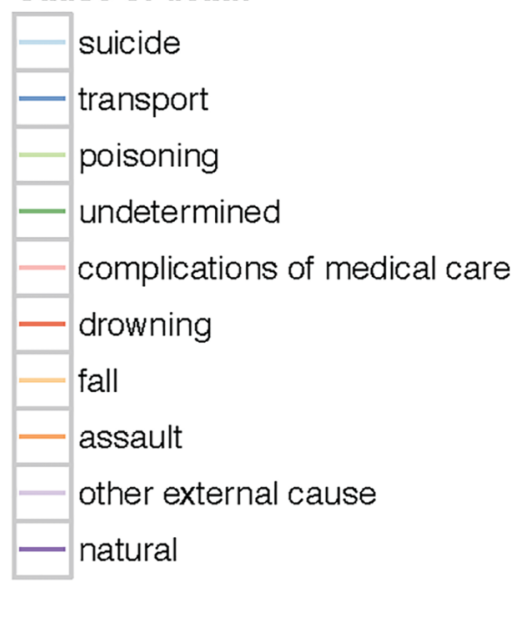

Figure 1 Duration of inquest cases: (A) overall, (B) by jurisdiction and (C) cause of death.

and pathology and toxicology reports, and delays in these steps may contribute to overall delays. ${ }^{24} 35$

Lengthy timelines for assaults and homicide cases-which averaged more than a year longer than other types of cases in our analysis-are a recognised problem with a known cause, although it has not previously been quantified in detail. ${ }^{1} 36$ Coroners usually hold off making findings until all criminal avenues have been exhausted (indeed, it is a requirement in many Australian jurisdictions). The rationale is that coronial proceedings may prejudice chances of a fair trial. 
Table 2 Predictors of case duration from a multiple regression model $^{*}$

\begin{tabular}{|c|c|c|}
\hline & B (months)* & $\begin{array}{l}95 \% \mathrm{Cl} \\
\text { (months) }\end{array}$ \\
\hline Male (ref: female) & -0.6 & -1.7 to 0.5 \\
\hline \multicolumn{3}{|l|}{ Age, years (ref: $26-40$ years) } \\
\hline$<18$ & 1.7 & -0.1 to 3.6 \\
\hline $18-25$ & -1.0 & -3.1 to 1.2 \\
\hline $41-60$ & -0.6 & -2.1 to 0.8 \\
\hline $61+$ & -4.2 & -5.6 to -2.7 \\
\hline \multicolumn{3}{|l|}{ Cause of deatht } \\
\hline Natural & -6.6 & -9.4 to -3.9 \\
\hline Intentional self-harm & -4.6 & -6.7 to -2.5 \\
\hline Drowning & -4.3 & -7.5 to -1.4 \\
\hline Undetermined & -3.6 & -6.9 to -0.4 \\
\hline Transport & -2.6 & -5.5 to -0.0 \\
\hline Poisoning & -2.4 & -4.7 to -0.1 \\
\hline Fall & -1.8 & -4.8 to 1.3 \\
\hline Other external cause & 1.5 & -1.9 to 4.7 \\
\hline Complications of medical care & 9.0 & 5.5 to 12.3 \\
\hline Assault & 12.2 & 7.8 to 17.0 \\
\hline \multicolumn{3}{|l|}{ Location of death (ref: major city) } \\
\hline Inner regional & -0.7 & -2.3 to 0.8 \\
\hline Outer regional & 4.3 & 1.5 to 7.6 \\
\hline Remote & 2.0 & -2.1 to 7.5 \\
\hline Very remote & -6.5 & -9.7 to -3.3 \\
\hline \multicolumn{3}{|l|}{ Jurisdiction (ref: New South Wales) } \\
\hline Northern Territory & -10.1 & -13.5 to -6.7 \\
\hline Australian Capital Territory & 3.3 & 0.3 to 6.5 \\
\hline Western Australia & 3.8 & 1.4 to 6.2 \\
\hline Tasmania & 4.3 & -1.2 to 10.2 \\
\hline Victoria & 7.5 & 6.2 to 8.8 \\
\hline Queensland & 8.2 & 6.5 to 9.9 \\
\hline South Australia & 11.9 & 9.7 to 14.0 \\
\hline Central court (ref: regional court) & 6.9 & 5.5 to 8.3 \\
\hline $\begin{array}{l}\text { Recommendation or warning issued (ref: } \\
\text { none issued) }\end{array}$ & 8.9 & 7.6 to 10.3 \\
\hline
\end{tabular}

${ }^{*}$ Coefficients represent the estimated number of additional (or fewer) months of case duration associated with the characteristic, relative to the reference group and adjusting for all other covariates. Imputation of missing data permitted all inquest cases in the sample $(n=5096)$ to be included in the multivariable analysis. tNo reference category because external cause categories were not mutually exclusive.

The relative slowness of investigations into iatrogenic deaths is more difficult to explain. As with assaults, coroners may defer holding an inquest until internal hospital investigations are complete. Securing busy doctors as expert witnesses can be challenging. Also, the causal factors leading to adverse medical outcomes can also be extremely difficult to disentangle, which may translate into more complex investigations and longer periods of deliberation by coroners. ${ }^{37}$ Whatever their source, delays in these cases demand action. Of the 239 deaths in our sample that were judged to be due to complications of medical care, families in one-third of them had to wait more than 4 years for findings.

The large inter-jurisdictional differences we observed resonate with previous research from Australia and the UK documenting significant geographic variation in the work of coroners. ${ }^{6} 1238$ Resource differences-or more precisely, the ratio of caseload to human and fiscal resources-are the most obvious explanation. However, other candidates, such as organisational culture, backlog awareness and the quality of case management and information systems also warrant consideration as potential culprits.

One performance indicator applied to Australian coroners' courts expects that no more than $10 \%$ of all cases should be open after a year and none should be open at 2 years. ${ }^{39}$ Because only $5 \%$ of all coronial cases proceed to inquest, we cannot assess overall performance against these standards. For inquest cases, however, every jurisdiction fell short of the 2-year standards-indeed four jurisdictions had more than $50 \%$ of inquests cases open at 2 years, and one had $90 \%$ of cases open.

The 10 months of additional closure time linked to cases that include recommendations is a provocative finding. The recommendation function of coroners in Australia is trumpeted as a public health benefit, but it has been little studied and is poorly understood. ${ }^{14}$ If coroners tend to make recommendations in the most difficult inquest cases, then unobserved case complexity may well confound this finding. To the extent the finding is both 'real' and causal, however, it raises new questions about whether the social gains from recommendations justify the public and private costs that flow from the additional time needed to generate them.

Finally, two other findings warrant mention because they challenge conventional wisdom. Death investigations in rural and remote areas are frequently handled by part-time coroners. There are concerns that these cases receive inferior treatment to their city-based counterparts. ${ }^{2}$ We found that investigations of deaths in remote communities closed more quickly than those occurring in cities, and that cases handled by central coroners' courts ran an average of 7 months longer. Unobserved differences in casemix, including some referral of complex cases from regional to central courts, may partly explain these findings, as may inferior quality of these investigations.

Our study has several limitations. First, despite the best efforts of NCIS custodians, data quality is imperfect, as exemplified by several anomalies with coding and uploading practices we encountered. Second, although the case characteristics we analysed are more detailed than those examined in previous reports, variables such as jurisdiction and cause of death are still relatively 'high level' in nature. More deep-seated factors than those we were able to observe-such as resource-to-caseload ratios and organisational culture-almost certainly influence timelines. Future research should try to assess these factors directly, although they are difficult to measure.

Third, as noted earlier, cases that proceed to inquest are not representative of coronial cases more generally-indeed, we focused our analysis on this subset of cases precisely because they have attracted the most serious concerns about duration. Finally, while it may be tempting in the context of a study of case duration to assume that 'faster is better', this is not necessarily so. Carefully gathering and evaluating the relevant evidence in death investigations takes time. When speed seriously compromises quality, more time may be desirable. Another profitable subject for further research would be the development of evidence-based criteria for stratifying new cases based on their complexity, as best that can be determined at an early stage, so that appropriate time targets can be tailored to each stratum.

Various proposals to address the problem of long coronial case duration have been made. They include greater auditing, monitoring, transparency and public accountability in relation to case backlogs; ${ }^{7}$ close oversight by the chief coroner of any case open for more than 1 year; ${ }^{5} 7$ immediate termination of the coronial investigation when a forensic pathologist's examination determines the death was due to natural causes; ${ }^{1}{ }^{2}$ fast-track criminal investigations; ${ }^{1}$ expanded use of interim 
coronial findings ${ }^{2}$ better communication with families on the progress of investigations; $;^{127824}$ and increased resources. ${ }^{24}$ England and Wales have recently turned to more rigorous standard setting and performance monitoring as a solution: rules introduced in mid-2013 set 6 months as the time period within which coroners are expected to complete inquests, unless there are extenuating circumstances. ${ }^{8}$

The potential for these and other reforms to reduce the burden of protracted death investigations should be determined by trial, followed by careful empirical evaluation. To be convincing, those evaluations will need to turn to more detailed measures and more sophisticated analytical methods than coronial systems throughout the British Commonwealth have embraced to date.

\section{What is already known on the subject}

- Many countries have identified the length of time it takes coroners to investigate deaths as a major problem, especially for investigations that proceed to inquest.

- Protracted death investigations adversely affect the deceased's family, undermine the integrity of vital statistics, and may leave the public exposed to unrecognised risks.

- The nature, extent and causes of delays are not well understood.

\section{What this study adds}

- Inquests in Australia take an average of 19 months to close, but there is a long right tail in the distribution of closure periods, with nearly one-quarter of cases taking more than 3 years.

- Average closure periods vary systematically by jurisdiction and cause of death.

- Application of standard epidemiologic methods to coronial cases sheds new light on the nature of delays, and these methods should be used to help pinpoint and address the sources of delays.

Acknowledgements The authors thank staff at the Victorian Department of Justice who manage the National Coroners Information System for providing the data and answering our many questions.

Contributors DMS, SJW, CK and GS came up with the idea for the analysis; DS obtained funding for the study; DMS and SJW designed the analysis; CK and GS coded key variables; SW and DS conducted the analysis; DMS wrote the first draft of the manuscript; SJW, CK and GS contributed important intellectual content to revisions of the manuscript.

Funding The study was funded by a Linkage Grant (LP100100307) and Laureate Fellowship (FL110100102 to DMS), both from the Australian Research Council. The research was conducted independently from the funder.

Competing interests None declared.

Ethics approval Human research ethics committee at the Victorian department of Justice.

Provenance and peer review Not commissioned; externally peer reviewed.

Data sharing statement Under the terms of use set by the National Coronial Information System (NCIS), the authors are not permitted to share the analytic dataset. However, NCIS regularly makes the dataset available to authorised users. Information on how to request the data can be found at http://www.ncis.org.au/ how-to-access-data-on-the-ncis/.
Open Access This is an Open Access article distributed in accordance with the Creative Commons Attribution Non Commercial (CC BY-NC 4.0) license, which permits others to distribute, remix, adapt, build upon this work non-commercially, and license their derivative works on different terms, provided the original work is properly cited and the use is non-commercial. See: http://creativecommons.org/ licenses/by-nc/4.0/

\section{REFERENCES}

1 Law Reform Committee, Parliament of Victoria. Inquiry into the Review of the Coroners Act 1985. September 2006. http://www.parliament.vic.gov.au/lawreform/ inquiries/article/1192 (accessed 10 Dec 2015)

2 Law Reform Commission of Western Australia. Review of Coronial Practice in Western Australia: Discussion Paper. Western Australia: Quality Press, 2011

3 Goudge ST. Inquiry into pediatric forensic pathology in Ontario. Vol 3. 2008. http:// www.attorneygeneral.jus.gov.on.ca/inquiries/goudge/report/index.html (accessed 10 Dec 2015).

4 Ministry of Justice. Coroners Act review: Proposals for reform-Cabinet paper 1 (undated). http://www.justice.govt.nz/publications/global-publications/c coroners-act-review-proposals-for-reform-cabinet-paper-one (accessed 10 Dec 2015)

5 Ministry of Justice. Coroners Act review: Proposals for reform-Cabinet paper 2 (undated). http://www.justice.govt.nz/publications/global-publications/c/ coroners-act-review-proposals-for-reform-paper-2 (accessed 10 Dec 2015).

6 Smith J. The Shipman Inquiry. Third report-death certification and the investigation of deaths by coroners. 14 July 2003. Command Paper Cm 5854. https://www.gov. uk/government/uploads/system/uploads/attachment_data/file/273227/5854.pdf (accessed 10 Dec 2015)

7 United Kingdom. Death certification and investigation in England, Wales and Northern Ireland. The report of a fundamental review. 2003. http://webarchive. nationalarchives.gov.uk/20131205100653/http:/www.archive2.official-documents. co.uk/document/cm58/5831/5831.pdf (accessed 10 Dec 2015).

8 Ministry of Justice. Implementing the coroner reforms in Part 1 of the Coroners and Justice Act 2009-Consultation on rules, regulations, coroners areas and statutory guidance. CP2/2013 (2013). https://consult.justice.gov.uk/digital-communications/ coroner-reforms (accessed 10 Dec 2015).

9 Department of Justice, Equality and Law Reform. Review of the coroner service. Dublin: Stationery Office, 2000. http://www.justice.ie/en/JELR/ReviewCoronerService. pdf/Files/ReviewCoronerService.pdf (accessed 10 Dec 2015).

10 Gallagher P. Backlog in coroners' courts. The Independent, 13 April 2014. http:/ www.independent.co.uk/news/uk/home-news/backlog-in-coroners-courts-bereavedfamilies-wait-up-to-seven-years-for-inquests-9256714.html (accessed 10 Dec 2015).

11 Fernandes D. Backlog of death certificates can tangle lives. Boston Globe, 17 June 2014. http://www.bostonglobe.com/business/2014/06/16/grieving-familiesface-insurance-financial-problems-from-delays-state-death-certificates/ CdqKPttNPvoDncewrajliN/story.html (accessed 10 Dec 2015).

12 Walter SJ, Bugeja L, Spittal MJ, et al. Factors predicting coroners' decisions to hold inquests. CMAJ 2012;184:521-8.

13 South Australian Coroner's Court. Annual Report of the State Coroner. Financia Year 2006-07. http://www.courts.sa.gov.au/OurCourts/CoronersCourt/Lists/ Coroners20Annual20Reports/Attachments/2/AR_2006-2007.pdf (accessed 10 Dec 2015).

14 Sutherland G, Kemp C, Bugeja L, et al. What happens to coroners recommendations for improving public health and safety? Organisational responses under a mandatory response regime. BMC Public Health 2014;14:732.

15 Cordner SM, Loff B. 800 years of coroners-have they a future? Lancet 1994:344:799-801.

16 Freckleton I, Ranson D. Death investigation and the coroner's inquest. Melbourne: Oxford University Press, 2006

17 Devis T, Rooney C. The time taken to register a death. Popul Trends 1997;88:48-55

18 Walker S, Chen L, Madden R. Deaths due to suicide: the effects of certification and coding practices in Australia. Aust N Z J Public Health 2008;32:126-30.

19 Elnour AA, Harrison J. Suicide decline in Australia: where did the cases go? Aust $N$ Z J Public Health 2009;33:67-9.

20 Barraclough BM, Shepherd DM. The immediate and enduring effects of the inquest on relatives of suicides. Br J Psychiatry 1977;131:400-4.

21 Biddle L. Public hazards or private tragedies? An exploratory study of the effect of coroners' procedures on those bereaved by suicide. Soc Sci Med 2003;56:1033-45.

22 Harwod D, Hawton K, Hope T, et al. The grief experiences and needs of bereaved relatives and friends of older people dying through suicide: a descriptive and case-control study. J Affect Disord 2002;72:185-94.

23 Freckleton I. Death investigation, the coroner and therapeutic jurisprudence. J Law Med 2007;15:1-12.

24 Federation of Community Legal Centres. Saving lives by joining up justice. Issues paper. March 2013. http://www.communitylaw.org.au/cb_pages/federation_reports. php (accessed 10 Dec 2015)

25 Ministry of Justice. Coroners statistics 2012-England and Wales: Ministry of Justice Statistics bulletin. 16 May 2013. https://www.gov.uk/government/uploads/system/ 
uploads/attachment_data/file/199793/coroners-statistics-bulletin-2012.pdf (accessed 10 Dec 2015).

26 Victoria Department of Justice. NCIS Annual Report, 2012-13. CD/13/308704. http://www.ncis.org.au/wp-content/uploads/2013/10/ NCIS-Annual-Report-FINAL-2012-13.pdf (accessed 10 Dec 2015)

27 Commonwealth Department of Health and Aged Care, 2001. Measuring Remoteness: Accessibility/Remoteness Index of Australia (ARIA). Occasional Papers: New Series Number 14.

28 Greenwood M. Reports on public health and medical subjects, No. 33, Appendix 1, The "error of sampling" of the survivorship tables. London: H.M. Stationary Office, 1926.

29 Efron B. Missing data, imputation and the bootstrap. J Am Stat Assoc 1994;89:465-75.

30 Shao J, Sitter R. Bootstrap for imputed survey data. J Am Stat Assoc 1996;91:1278-88.

31 van Buuren S, Groothuis-Oudshoorn K. MICE: Multivariate imputation by chained equations in R. J Stat Softw 2011;45:1-67.

32 Studdert DM, Cordner SM. Impact of coronial investigations on cause of death determinations in Australia, 2000-07. Med J Aust 2010;192:444-7.
33 Wagenaar AC, Burris SC, eds. Public health law research: theory and methods. San Francisco, CA: Jossey-Bass, 2013.

34 Office of the State Coroner of Western Australia. Annual report 2006-07. http:// www.coronerscourt.wa.gov.au/_files/ar2006-07.pdf (accessed 10 Dec 2015).

35 South Australian Coroner's Court. Annual Report of the State Coroner. Financial Year 2007-08. http://www.courts.sa.gov.au/OurCourts/CoronersCourt/Lists/ Coroners20Annual20Reports/Attachments/3/AR_2007-2008.pdf (accessed 10 Dec 2015)

36 Abernethy J, Baker B, Dillon H, et al. Waller's Coronial Law and Practice in New South Wales. 4th edn. Lexis-Nexis, 2010.

37 Mello MM, Studdert DM. Deconstructing negligence: the role of individual and system factors in causing medical injuries. Georgetown Law J 2008;96: 599-623.

38 Davis G, Lindsey R, Seabourne G, et al. Experiencing inquests-Home Office research study 241. London: Home Office Research, Development and Statistics Department, 2002

39 Steering Committee for the Review of Government Service Provision. Report on Government Services 2013. Vol. 1. Canberra: Productivity Commission, 2013.

\section{How seat belts save lives}

The National Highway Traffic Safety Administration estimates 15000 lives are saved each year in the USA because of seat belts. Seat belts reduce serious crash-related injuries and deaths by about $50 \%$ and are even more effective when used with air bags. They work by keeping occupants in the car; by restraining the sturdiest parts of the body they spread collision forces; and they slow the body from hitting solid structures, protecting the brain and spinal cord. The use rate in 2014 was $87 \%$. Primary seat belt laws increase use by about $10 \%$ but only 34 states have such laws.

\section{KangaTech hopes to improve injury prevention}

KangaTech is an Australian company that hopes to improve injury prevention in sports by 'tracking a number of proven, modifiable and easily testable risk factors, and then improve these risk factors through targeted intervention.' The company's injury prevention platform is a combination of cloud-based software and 'smart training' equipment. It has been used by one football club since 2011. Subsequently, some estimate the team has had one of the best (lowest) soft tissue injury rates in Australian sport.

\section{Personal injury law firms donate bike helmets}

Two Canadian personal injury law firms are part of the Ontario Trial Lawyers Association (OTLA) Bike Helmets on Kids (BHK) campaign. Their goal is to distribute 4000 bicycle helmets to children in Ontario. They have involved a 'Lidz on Kidz' safety educator to ensure proper fitting. Since 2002 when the campaign began, about 19000 helmets have been distributed, all of which were purchased by OTLA lawyers and their firms. The BHK campaign has been recognised with many awards. 